\title{
How much should we spend on healthcare?
}

\author{
Fiona Godlee editor in chief
}

The BMJ

What's the right amount of spending on healthcare? And how does the UK's spending compare with that of its European neighbours? For a long time the view was that the UK spent less than the European average. But new estimates that are based on new accounting methods give a different picture. As John Appleby and Ben Gershlick explain (doi:10.1136/bmj.j3568), the new figure is $9.8 \%$ of GDP, which puts the UK ninth in the European Union league table and is pretty much bang on the EU average (though at the bottom end of the weighted average, if you're into the detail).

The authors emphasise that the figures can't tell us what we should spend but can tell us what we could spend. To be average for the EU, UK healthcare spending would have to reduce by $£ 2$ bn, while to be on a par with Sweden it would need to increase by $£ 24$ bn.

The figures are for public and private spending combined, and they newly include spending on health related social and long term care, which explains much of the increase. They also show the amounts spent on different types of care. Sweden, the Netherlands, and Belgium spend relatively less on curative and more on long term care, a finding that the authors say could begin an important conversation about how we transition from traditional to new approaches and maximise the benefits of the UK's scarce resources.

No resource is scarcer or arguably more precious than the people who work in healthcare. So you'd think employers would do all they could to make them feel valued. Not so, as our regular columnists David Oliver and Margaret McCartney have to observe all too often. And this week trainee doctor Rachel Clarke gives a fresh and fiery report of this unacceptable situation (doi:10.1136/bmj.j3651). Despite promises made after the junior doctors' contract dispute last year, NHS trusts are still treating juniors as if they are expendable, she says, expecting them to start work without a contract or being told what their hours will be or what they will be paid. It's down to the 152 chief executives of acute care hospital trusts to act on their responsibilities, she says. We have sent her column to each one of them and asked for their response, and we'd like to hear your thoughts and stories too, in rapid responses.

\section{To wrap up}

A small piece of good news. Amid understandable concerns about your working lives, some of you find time to write to us about the environmental credentials of the plastic wrapper around the print $B M J \mathrm{~s}$. We have tried many things over the years, including most recently oxydegradable polywrap, which has some advantages but requires oxygen to degrade down to plastic fragments. I'm pleased to say that next month we move to a fully recyclable polywrap. One reader will be sorry (doi:10. $1136 / \mathrm{bmj} . j 3632$ ), as to the best of our knowledge the new polywrap has no luminescent qualities. 